\title{
O SUPREMO TRIBUNAL FEDERAL E O DISCURSO DA IMPLEMENTAÇÃO DE POLÍTICAS PÚBLICAS NA JURISPRUDÊNCIA BRASILEIRA: A ATUAÇÃO JUSTIFICADA NA OMISSÃ ${ }^{1}$
}

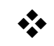 \\ Mônia Clarissa Hennig Leal \\ Universidade de Santa Cruz do Sul-UNISC-Brasil \\ Maria Valentina de Moraes \\ Universidade de Santa Cruz do Sul-UNISC - Brasil
}

\section{Resumo}

A importância da formulação de políticas públicas que assegurem direitos fundamentais sociais, em especial o direito à saúde - aqui analisado - é inegável. No tocante ao direito à saúde, observa-se que uma da principais formas de concretização do direito se encontra na formulação e execução de tais políticas, dado seu caráter coletivo, visando a garantia ao cidadão de direitos assegurados em nossa Constituição Federal. Contudo, é crescente o número de demandas judiciais buscando a realização desse direito, o qual, embora encontre respaldo no rol de direitos sociais do artigo $6^{\circ}$ da Constituição brasileira, ainda não tem sua completa concretização. Diante desse fator, o presente artigo busca analisar, com base na jurisprudência do mais alto Tribunal brasileiro, como tem ocorrido a intervenção, por parte do Supremo Tribunal Federal, em matéria de políticas públicas. A omissão ou inércia governamental é o pano de fundo à intervenção, servindo como justificativa para que o Poder Judiciário determine uma atuação do Poder Público em nome da proteção de preceitos constitucionais. Pretende-se analisar, portanto, como é tratada referida intervenção e como se coloca o Princípio da Separação de Poderes na relação interventiva que se estabelece. Buscase, dessa forma, compreender como ocorre - e se ocorre - a determinação de criação e execução de políticas públicas por parte do Poder Judiciário em nosso país.

Palavras-chave: Direitos Sociais; Jurisdição Constitucional; Omissão; Políticas Públicas; Supremo Tribunal Federal.

\footnotetext{
${ }^{1}$ Este artigo é resultante das atividades do projeto de pesquisa "Dever de proteção (Schutzpflicht) e proibição de proteção insuficiente (Untermassverbot) como critérios para o controle jurisdicional (qualitativo) de Políticas Públicas: possibilidades teóricas e análise crítica de sua utilização pelo Supremo Tribunal Federal e pela Corte Interamericana de Direitos Humanos", financiado pelo CNPq (Edital Universal - Edital 14/2014 - Processo 454740/2014-0) e pela FAPERGS (Programa Pesquisador Gaúcho - Edital 02/2014 - Processo 2351-2551/145), onde os autores atuam na condição de coordenadora e de participante, respectivamente. A pesquisa é vinculada ao Grupo de Pesquisa "Jurisdição Constitucional aberta" (CNPq) e desenvolvida junto ao Centro Integrado de Estudos e Pesquisas em Políticas Públicas - CIEPPP (financiado pelo FINEP) e ao Observatório da Jurisdição Constitucional Latino-Americana (financiado pelo FINEP), ligados ao Programa de Pós-Graduação em Direito - Mestrado e Doutorado da Universidade de Santa Cruz do Sul - UNISC.
} 


\section{INTRODUÇÃO}

As políticas públicas possuem grande importância em nosso sistema, configurando-se como meios pelos quais direitos fundamentais sociais são garantidos ao cidadão, através de ações programadas do Estado, buscando o atendimento da coletividade. Assim, fazer com que as políticas públicas sejam efetivadas e, consequentemente, também os direitos fundamentais sociais, é de grande importância.

Contudo, é constante a busca pelo Poder Judiciário na tentativa de serem garantidos direitos como a saúde e a educação, direitos esses essenciais à pessoa. Busca-se, então, analisar o papel que vem sendo desempenhado pelo Poder Judiciário, com ênfase na atuação do Supremo Tribunal Federal, no tocante à intervenção na implementação de políticas públicas.

Nesse ínterim, pretende-se analisar as relações que se estabelecem entre os Poderes Legislativo e Executivo com a intervenção judicial do mais alto Tribunal brasileiro, sob a ótica da inércia governamental - argumento frequentemente utilizado para justificar a atuação judicial. Sendo assim, busca-se compreender como a omissão do Poder Público configuraria uma afronta a direitos fundamentais sociais e, portanto, a própria Constituição Federal brasileira.

Dessa forma, o argumento relativo à omissão dos demais Poderes na execução de políticas públicas assume grande relevância nas discussões travadas quanto à intervenção do Poder Judiciário em uma matéria que, a princípio, compete aos Poderes Legislativo e Executivo. A atuação da Corte, como se pretende demonstrar, é sustentada, por seus Ministros, na omissão pública e desrespeito aos postulados constitucionais.

\section{A OMISSÃO DO PODER EXECUTIVO: JUSTIFICATIVA QUE AUTORIZA A INTERVENÇÃO DO JUDICIÁRIO EM MATÉRIA DE IMPLEMENTAÇÃO DE POLÍTICAS PÚBLICAS}

O Supremo Tribunal Federal, em inúmeras decisões envolvendo a concretização de direitos sociais por meio de políticas públicas, já se manifestou quanto a sua capacidade em intervir quando houver o desrespeito a algum direito fundamental social. A principal justificativa para sua atuação se encontra na omissão dos demais poderes incumbidos de 
realizarem os direitos abarcados no rol do artigo $6^{\circ}$ e em partes esparsas ${ }^{2}$ da Constituição Federal brasileira.

As decisões discutem eventual ofensa ao Princípio da Separação de Poderes, entendendo o Supremo Tribunal Federal que não estaria configurada referida afronta, uma vez que quando omissos os Poderes incumbidos da promoção de direitos sociais, estaria o Judiciário apto a intervir e garantir, então, a concretização desses direitos protegidos constitucionalmente.

Nesse sentido, leciona Mendes (2010, p. 483), no que tange aos direitos sociais e sua alargada previsão constitucional:

\begin{abstract}
atualmente, a Constituição brasileira não apenas prevê expressamente a existência de direitos fundamentais sociais (art. $6^{\circ}$ ), especificando seu conteúdo e forma de prestação (arts. 196, 201, 203, 205, 215, 217, entre outros), como também não faz distinção entre os direitos e deveres individuais e coletivos (Capítulo I do Título II) e os direitos sociais (Capítulo II do Título II), ao estabelecer que os direitos e garantias fundamentais tem aplicação imediata $\left(\mathrm{CF} / 88\right.$, art. $\left.5^{\circ}, \S^{\circ}\right)$.
\end{abstract}

Dessa forma, em razão da natureza prestacional dos direitos sociais, estes demandam do Estado uma ação que garanta a sua realização. Tais direitos tem como característica a intervenção desses órgãos estatais e, diferentemente dos direitos de defesa ${ }^{3}$, não tem na omissão pública a sua efetividade. Ou seja, eles compreendem um direito à prestações positivas e tratam-se de normas jurídicas vinculantes, dependendo tal vinculação do nível de abstração ou determinação destes direitos.

Ainda, quanto ao caráter prestacional dos direitos sociais, CARA (2010, p. 24) ressalta que:

los derechos prestacionales en sentido material se identifican y necesitan de una acción positiva de carácter factico por parte de los poderes públicos o articulación de normas y decisiones públicas, pero necesariamente se debe caracterizar a través de unas medidas de protección prestacional de las posiciones jurídicas constituidas por cualquier derecho fundamental que incluye tanto el análisis de las consecuencias de su configuración normativa como de las circunstancias de su aplicación a los casos concretos.

\footnotetext{
${ }^{2}$ Como exemplo de direitos sociais que encontram-se em diferentes artigos de nossa Constituição Federal encontram-se os direitos trabalhistas, elencados no artigo $7^{\circ}$ da Constituição de 1988 e também o direito à boa administração pública, o qual estaria elencado de forma tácita no artigo 37 da Constituição pátria.

${ }^{3}$ Alguns autores defendem, entretanto, no que tange aos os direitos de defesa, que esses não exigem do Estado apenas uma abstenção, como classicamente são conhecidos, mas também uma atuação que vise sua proteção para que, de fato, esses direitos encontrem-se garantidos pelo Estado. Nesse sentido, cf. QUEIROZ, Cristina. $O$ princípio não reversibilidade dos direitos fundamentais sociais: princípios dogmáticos e prática jurisprudencial. Coimbra Editora, 2006. p. 18 e 22.
} 
Seu caráter prestacional, como se percebe, faz com que a sua efetividade dependa de mecanismos que garantam o acesso a tais direitos, demandando ações e não apenas a não intervenção do Poder Público para que sejam preservados e concretizados. Complementa o autor ainda, quanto à vinculação que decorre das Constituições na concretização desses direitos:

las Constituciones vinculan a los poderes públicos exigiéndoles la implementación de políticas públicas de carácter social, ya que la lenguaje constitucional impone al Estado acciones para asegurar, promover, organizar, coordinar y subsidiar acciones de carácter social mediante la adopción de medidas legislativas o de otra naturaleza en el marco de los recursos disponibles para la realización gradual y progresiva de los derechos sociales en presencia. (CARA, 2010, p. 76).

Pode se dizer, dessa forma, que a Constituição Federal brasileira consagrou uma série de direitos fundamentais sociais e vinculou os Poderes do Estado no que condiz com a sua garantia e proteção. Decorreu, desse extenso rol de direitos fundamentais abarcados por nossa Constituição Federal, problemáticas quanto a sua efetivação frente a diversos fatores, dentre eles a impossibilidade de garantia plena de todos os direitos constitucionais em razão de uma limitação financeira e orçamentária.

Por tal razão, foi crescente a judicialização destes direitos. Construiu-se, dessa maneira, uma contradição entre as diversas previsões constitucionais sobre direitos fundamentais e a efetividade, na prática, desses postulados (HACHEM, 2014). Em uma análise da Carta Magna brasileira, Hachem (2014, p. 287), bem observou que:

\footnotetext{
la cuestión se tornó aún más compleja frente a la disposición inscrita en el $\S 1^{\circ}$ del art. $5^{\circ}$ de la Constitución Federal do Brasil, según la cual "las normas definidoras de derechos y garantías fundamentales tienen aplicación inmediata".

La literalidad de dicho dispositivo, sumada a la aspiración de extraer plena eficacia de las determinaciones constitucionales en materia de derechos fundamentales económicos y sociales, condujo a parte de la doctrina a sostener la posibilidad de postular judicialmente, ante las omisiones de la Administración Pública, la realización de estos derechos.
}

Sendo assim, diante do fato de que a Constituição pátria trouxe em seu conteúdo uma previsão alargada de direitos fundamentais, é preciso que sejam criadas ações que visem à realização desses direitos e, dentre elas, encontram-se as políticas públicas. Estas políticas se prestam a garantir uma das finalidades do Estado, qual seja, o acesso e a promoção dos direitos fundamentais e sociais a toda e qualquer pessoa.

Assim, diante da necessidade de que sejam criados mecanismos de ação - por parte do Poder Público - que efetivem os direitos fundamentais sociais, pode se afirmar que "o 
administrador está vinculado às políticas públicas estabelecidas na Constituição Federal; a sua omissão é passível de responsabilização e a sua margem de discricionariedade é mínima, não contemplando o não fazer" ${ }^{4}$, existindo, de tal forma, uma limitação à margem de atuação do poder público 5 :

o Estado não poderá demitir-se do mandato constitucional, juridicamente vinculante que lhe foi outorgado (...) e que representa (...) fator de limitação da discricionariedade de Poder Público, cujas opções, tratando-se de proteção à saúde, não podem ser exercidas de modo a comprometer, com apoio em juízo de simples conveniência ou de mera oportunidade, a eficácia desse direito básico de índole social.(BRASIL, STF, 2010)

É importante, contudo, tecer uma diferenciação entre a omissão dos Poderes Públicos e o não agir motivado, onde por alguns motivos determinada decisão, ou mesmo ação, não é tomada. Rodrigues (2010, p. 43), bem retrata essa diferença, ressaltando que "as políticas públicas podem ser estudadas tanto da perspectiva da ação do Governo (o que o Governo faz) quanto da inação (o que o Governo não faz) diante de algum problema", realizando ainda uma distinção entre inação e ausência de decisão:

vale notar que a inação (ou a não decisão) não significa simplesmente ausência de decisão do Governo sobre uma questão que está na agenda política; mas, sim, que determinadas questões se deparam com obstáculos diversos (inclusive políticos) que as impedem de penetrar na agendar pública. (RODRIGUES, 2010, p. 43)

Na omissão, ou inércia governamental - injustificada, salienta-se -, é que se encontra a justificativa do mais alto Tribunal brasileiro para determinar aos demais Poderes que sejam efetivadas as políticas públicas já criadas ${ }^{6}$. Nessa perspectiva, a atuação do órgão pauta-se na

\footnotetext{
${ }^{4}$ Considerações do Ministro Gilmar Mendes, em voto proferido na Suspensão de Tutela Antecipada 175AgR/CE, no ano de 2010 - decisão que firmou diversos parâmetros referentes ao direito à saúde no Brasil.

5 Neste sentido, vide art.69 da Lei 9.394/96 (percentuais mínimos investidos em educação); art. 31 da Lei 8.080/90 (destinação do orçamento da Seguridade Social), art. 3º p.ú., inciso III, da Lei 10.741/03 (destinação privilegiada de recursos públicos);art. 4, p. ú., alínea "c", da Lei 8.069/90 (preferência na formulação de Políticas Sociais Públicas específicas); art. $5^{\circ}$ e seguintes, da Lei Complementar n. 141/2012 (valores mínimos a serem aplicados anualmente em ações e serviços públicos da saúde), entre outros; Ainda, necessária a referência às diversasdisposições da Constituição Federal que vinculam o administrador à implementação de políticas públicas como, por exemplo:art. 195 (financiamento da seguridade social), art. 198, § 2 (recursos mínimos de aplicação nas ações voltada à saúde),art.211 (vinculação aos regimes de ensino na promoção da educação), art.212, "caput"(percentuais a serem aplicados na manutenção da educação), bem como a redação do art. 85, inciso VI, o qual inclui como crime de responsabilidade os atos que atentem contra à lei orçamentária.

${ }^{6}$ Também na Suspensão de Tutela Antecipada 175- AgR/CE, o Ministro Gilmar Mendes ao proferir seu voto enfatizou que não há a criação de políticas públicas pelo Poder Judiciário, mas a determinação de que as já criadas sejam colocadas em prática. Assim aduziu: "no Brasil, o problema talvez não seja de judicialização ou, em termos mais simples, de interferência do Poder Judiciário na criação e implementação de Políticas Públicas,
} 
ideia da necessidade de suprir a lacuna existente, pois, como bem coloca Monteiro (2010, p. 168), "se um dos poderes não exerce o seu papel, compete aos outros suprimir sua falta", buscando que não haja uma deficiência das prestações estatais.

Partindo-se desse argumento de intervenção, interessante compreender a lógica utilizada na jurisprudência da Corte brasileira, da qual, como referido, pode se extrair que, diante de uma omissão quanto à realização de diretos que vinculam o administrador, haverá a intervenção do Poder Judiciário, sem qualquer afronta ao Princípio da Separação de Poderes.

\subsection{A construção jurisprudencial do Supremo Tribunal Federal no tocante à inércia governamental}

São claros os argumentos do mais alto Tribunal pátrio ao analisar a possibilidade de intervir frente a uma violação aos direitos fundamentais sociais, desrespeitando a Magna Carta brasileira. Tal posicionamento se extrai, inclusive, do afirmado pelo Ministro Eros Grau $^{7}$ (BRASIL, STF, 2010) ao afirmar que "o desrespeito a Constituição tanto pode ocorrer mediante ação estatal quanto mediante inércia governamental", deixando, no segundo caso, aberta a porta a análise do Poder Judiciário quanto à questão.

O principal argumento invocado pelo Poder Executivo quando a discussão é levada ao conhecimento do Poder Judiciário é o de que, com a determinação, pelo Judiciário, de um facere aos demais Poderes, estaria a Corte ofendendo o Princípio da Separação de Poderes. Observa-se, contudo, que a jurisprudência do Supremo Tribunal Federal, de forma reiterada ${ }^{8}$, demonstra entender que diante de uma violação da Constituição Federal - consolidada com a chamada inércia governamental -, o Judiciário estaria agindo de forma legítima, sem qualquer ofensa à Separação de Poderes.

Há que se considerar, entretanto, que o próprio caráter dos direitos sociais e a sua constitucionalização "entregam" ao Poder Judiciário a análise de questões que envolvam a sua violação e proteção. Dessa forma, dada a função de guarda da Constituição Federal outorgada

pois o que ocorre, na quase totalidade dos casos, é apenas a determinação judicial do efetivo cumprimento de políticas públicas já existentes" (STA 175- AgR/CE, Ministro Gilmar Mendes, 2010).

${ }^{7}$ RE 603.575-AgR/SC, 2010.

${ }^{8}$ MAUS (2000, p. 192) traça uma crítica ao que chama de "superego constitucional" e a autorreferência nos julgados dos Tribunais, colocando que "enquanto a uma prática judiciária quase religiosa corresponde uma veneração popular da Justiça, o superego constitucional assume traços imperceptíveis, coincidindo com formações 'naturais' da consciência, tornando-se portador da tradição no sentido atribuído por Freud. Por conta de seus métodos específicos de interpretação constitucional, atua o TFC menos como 'Guardião da Constituição' do que como garantidor da própria história jurisprudencial, à qual se refere legitimamente de modo autoreferencial". A crítica aplica-se bem ao que ocorre na jurisprudência pátria, pois são frequente, nas decisões do Supremo Tribunal Federal, referências a julgados pregressos, reforçando o entendimento adotado pela Corte anteriormente. 
ao Supremo, diante do descumprimento de um preceito fundamental, o Poder Judiciário seja chamado a intervir nesses casos.

A própria Constituição, em seu artigo $102^{9}$, tratou de aumentar sobremaneira o campo de atuação do Judiciário - no caso, do Supremo Tribunal Federal -, diante da possibilidade de que esse analise toda violação aos direitos fundamentais. No que diz respeito a esse protagonismo judicial que estaria, em tese, alicerçado na própria Constituição Federal brasileira, salientam Tavares e Buck (2007, p. 177), que "não há como rechaçar que a existência de uma Constituição é responsável, por si só, por conceder ao Judiciário um maior protagonismo institucional, na medida em que o incumbe de realizar o dito controle de constitucionalidade".

Ainda, a ideia de intervenção judiciária diante da falta dos demais poderes do Estado, é construída, ainda, pelo Ministro Gilmar Mendes (BRASIL, STF, 2010), através de dados obtidos com a Audiência Pública - Saúde, ao afirmar que "o Judiciário não está criando política pública, mas apenas determinando o seu cumprimento". Pode se extrair dessa constatação que o que ocorre - ao menos no discurso do Supremo Tribunal Federal -, é a existência de uma política pública, mas o seu descumprimento pela Administração Pública, o que se dá, por certo, pela sua inércia.

Como demonstrado, o discurso encontrado na jurisprudência do Supremo Tribunal Federal assenta sua legitimidade no argumento da inércia governamental e consequente afronta aos direitos fundamentais sociais por tal omissão. Todavia, cabe questionar como se consolida, na prática, a teoria apresentada nos votos dos Ministros do mais alto Tribunal federal.

\section{O DISCURSO DA IMPLEMENTAÇÃO DE POLÍTICAS PÚBLICAS E A TUTELA DO DIREITO SOCIAL DE FORMA SUBJETIVA}

Embora o Supremo Tribunal Federal, nas decisões em que firmou entendimento quanto à possibilidade do Poder Judiciário intervir e determinar a implementação de políticas públicas - já criadas - aos demais Poderes, constantemente reafirme essa possibilidade, o discurso da Corte não corresponde a sua decisão final.

Os votos analisados nos permitem perceber que o embasamento utilizado pelos Ministros difere da tutela concedida ao final da decisão e, também, do pedido que é realizado pela parte. Ainda que os julgados discutam a possibilidade de que o Poder Judiciário

\footnotetext{
${ }^{9}$ Art. 102. Compete ao Supremo Tribunal Federal, precipuamente, a guarda da Constituição (...).

Barbarói, Santa Cruz do Sul, Edição Especial n.47, p.<289-302>, jan./jun. 2016
} 
determine aos Poderes Legislativo e Executivo a tomada de ações que efetivem políticas públicas, a tutela final concede apenas o direito de forma individualizada, como requerido pelo particular.

Se estabelece, dessa forma, em razão dos argumentos utilizados para fundamentar os votos, a ideia de que o Supremo Tribunal Federal realiza o controle jurisdicional de políticas públicas no país, quando, de fato, não o faz. Leal (2013, p. 12), coloca, no que se refere a essa atuação:

\begin{abstract}
Percebe-se, assim, um deslocamento do foco da decisão, que é transferido para uma perspectiva mais individual do que coletiva; por tratar-se de um direito fundamental e por estar intimamente ligado com os valores inerentes a dignidade da pessoa humana, o Judiciário encontra-se autorizado a adotar provimentos jurisdicionais para a sua concretização.

Disto decorre, por sua vez, que, nestes casos, não se tem propriamente um controle de Política Públicas, mas sim a realização de um direito constitucionalmente assegurado.
\end{abstract}

Embora se pretenda a concessão de um direito de forma individual, são analisados os argumentos da ofensa ao Princípio da Separação de Poderes e dos entraves encontrados na reserva do possível, contudo, utilizando-se de uma ótica da realização de direitos fundamentais sociais, mas em uma perspectiva de coletividade. O Ministro Gilmar Mendes (BRASIL, STF, 2010), nesse sentido, quanto a necessidade de realização do que chama de "escolhas trágicas" que decorrem da escassez de recursos, coloca:

a escolha da destinação de recursos para uma política e não para outra leva em consideração fatores como o número de cidadão atingidos pela política eleita, a efetividade e a eficácia do serviço a ser prestado, a maximização dos resultados etc." (STA 175- AgR/CE, Ministro Gilmar Mendes, 2010)

No decorrer dos votos proferidos pelos Ministros do mais alto Tribunal brasileiro, são debatidas as possibilidades, quando trata-se de implementar uma política pública ou mesmo realizar o seu controle, no entanto, pouco se fala acerca da efetivação da dimensão subjetiva do direito em questão - que, ao fim e ao cabo, é o resultado alcançado pela decisão. Daí decorrem algumas consequências que afetam o modo como se concretizam os direitos elencados no artigo $6^{\circ}$ da Constituição Federal brasileira, se fazendo necessário traçar algumas distinções entre os conceitos utilizados nas decisões. 


\subsection{A diferenciação necessária entre implementação de políticas públicas e realização de direitos sociais}

A execução de políticas públicas presta-se, assim, a garantir, a um maior número de pessoas, algum direito social garantido constitucionalmente, demandando, entretanto, em razão da escassez de recursos, que sejam analisadas diferentes questões em sua criação. Mendes (2010, p. 485), no que diz respeito à formulação de políticas públicas e as escolhas alocativas a serem realizadas pelo gestor público, ressalta que:

a garantia mediante políticas sociais e econômicas ressalva, justamente, a necessidade de formulação de políticas públicas que concretizem o direito à saúde por meio de escolhas alocativas. É incontestável que, além da necessidade de se distribuir recursos naturalmente escassos por meio de critérios distributivos, a própria evolução da medicina impõe um viés programático ao direito à saúde, pois sempre haverá uma nova descoberta, um novo exame, um novo prognóstico ou procedimento cirúrgico, uma nova doença ou a volta de uma doença supostamente erradicada.

As políticas públicas tem, como um de seus objetivos, portanto, a concretização dos direitos sociais, servindo como uma das possíveis formas de garantir que esses direitos constitucionais tenham sua dimensão coletiva garantida. Na doutrina, muitas são as definições ao que estaria abarcado no conceito de políticas públicas e, dentre elas, algumas destacam-se, sendo, nas palavras de Bitencourt (2013, p. 52), apresentadas com frequência as seguintes:

uma política pública permite distinguir o que o governo pretende fazer e o que de fato realmente realiza; uma política pública envolve vários níveis de decisão não se restringindo apenas aos atores formais, embora seja materializada através dos governos; uma política pública tende a abranger as leis e regras, mas não se limita a elas; uma política pública é uma ação intencional com objetivos a serem alcançados; e, embora possua resultados a curto prazo, em regra seu gozo é a longo prazo.

Adota-se, para esta análise, portanto, o conceito que Leal (2014, p. 08) apresenta, segundo o qual as políticas públicas configuram-se como "meios (escolhas políticas) para a realização dos fins propostos, traduzidos na figura dos direitos fundamentais (fixados juridicamente)". Assim, como exposto, não há nas decisões analisadas, que sustentam o discurso da implementação de políticas públicas, a real determinação de efetivação dessas como meios de execução dos direitos fundamentais sociais. Se determina, a título exemplificativo, a concessão de um medicamento pleiteado pelo particular - que busca essa tutela - e não a criação ou a execução de uma política pública que garanta a distribuição daquele referido medicamento. 
Já no que tange aos direitos fundamentais sociais, há que ser considerado que os mesmos, em razão do seu caráter prestacional, exigem do Estado uma atuação e não uma simples abstenção. Hachem (2014, p. 295) salienta que os direitos fundamentais:

\begin{abstract}
no son derechos simples, a los cuales corresponde apenas un deber respectivo. Son haces de posiciones ius fundamentales, es decir, derechos que conceden a sus titulares un conjunto variado de posiciones jurídicas dotadas de tutela reforzada, y que imponen al Poder Público una gama diversificada de obligaciones correlativas a las diferentes funciones ejercidas por cada una de esas posiciones.(Grifos no original)
\end{abstract}

Queiroz (2006, p. 28), também aponta, referindo a determinação constitucional de que se implementem políticas públicas e que se realizem os direitos sociais, que:

a Constituição obriga os poderes públicos à aprovação de medidas legislativas e de
outra natureza no quadro dos "recursos disponíveis" em ordem à realização
progressiva e gradual dos direitos e presença. O mesmo é dizer: adopta (sic) uma
política de reconhecimento de "direitos" acompanhada da obrigação de
implementação de "políticas públicas" de concretização e realização desses direitos
no caso particular.
Esta "estratégia" não afasta a possibilidade de "justiciabilidade" dos direitos
fundamentais sociais, mas limita-a fortemente. (Grifos no original)

Sendo assim, os direitos fundamentais sociais, dada a sua importância e seu conteúdo, permitem que sua concretização ocorra por diversos meios, seja pela criação e implementação de políticas públicas, seja pela sua tutela individualizada - como se pode se extrair das decisões do Supremo Tribunal Federal que determinam a realização de direitos sociais ao particular, sem que haja, de fato, a criação de uma política pública.

Referida possibilidade, faz com que as decisões proferidas pela Corte incidam diretamente nas finanças públicas e, por terem sido concedidas de forma individualizada e não por meio de uma política pública planejada e que possua previsão orçamentária, acarretam custos maiores ao Estado. Apresenta-se o levantamento realizado pela Advocacia Geral da União quanto à intervenção Judicial na saúde pública no Brasil, onde constam os gastos gerados com as decisões envolvendo a garantia individualizada do direito à saúde, através da determinação do fornecimento de medicamentos:

o contrato de transporte aéreo (necessário para a entrega da medicação na residência do paciente) [...], no ano de 2011 custou R \$ 1.620.841,62 (um milhão, seiscentos e vinte mail, (sic) oitocentos e quarenta e um reais e sessenta e dois centavos) e no ano de 2012 foi de R\$ 1.965.435,39 (um milhão novecentos e sessenta e cinco mil, quatrocentos e trinta e cinco reais e trinta e nove centavos). Esses gastos traduzem o custo adicional a cada ano pelo fato de se ter comprar não programadas, voltadas ao 
atendimento de pacientes de modo individual e com entrega em suas respectivas residências.

Outrossim, é inegável que a intervenção do Poder Judiciário, na figura do Supremo Tribunal Federal, acaba trazendo aos cofres públicos grandes impactos. Por outro lado, se referidos medicamentos concedidos pela via judicial, a exemplo, estivessem dentre de um planejamento estratégico de uma política pública, tais custos poderiam ser minimizados, contando com uma previsão orçamentária e estando isentos de gastos que só existem em razão daquele concessão individualizada.

\section{Conclusão}

Por todo o exposto, em razão da importância dos direitos fundamentais sociais para a garantia do direito à vida e a dignidade da pessoa humana, e das políticas públicas como meios de efetivação desses, analisar como vem ocorrendo, de fato, a realização desses, se faz imprescindível.

A omissão ou inércia governamental, surge, dessa forma, como uma legitimadora da atuação do Supremo Tribunal Federal, o que pode ser extraído dos votos dos Ministros analisados. Essa omissão acarretaria, assim, uma ofensa aos direitos assegurados em nossa Constituição Federal e também à ela, autorizando o Poder Judiciário a manifestar-se quanto as questões em que configurou-se essa falta dos demais Poderes.

Ainda, pode se afirmar que os Poderes Executivo e Legislativo - aqui, voltando-se a figura do Poder Executivo e da Administração Pública -, encontram-se vinculados a realização dos direitos fundamentais sociais e, para tanto, devem promover políticas públicas que os efetivem na prática.

Por outro lado, a atuação do Poder Judiciário, ainda que revestida da ideia de que há no Brasil o controle de políticas públicas por parte do Supremo Tribunal Federal, não está, de fato, contribuindo para que sejam concretizadas políticas públicas já existentes. As decisões se restringem, na prática, a conceder um direito social de forma individual, como foi buscado pela parte, não determinando que a Administração Pública execute qualquer política pública relativa aquele pedido.

Pode se dizer, desta forma, que, embora a omissão do Poder Público sirva como justificativa à atuação do Poder Judiciário para a realização do controle jurisdicional de políticas públicas, esse controle não existe de fato. O que existe é a violação de um direito 
social de um particular que, ao acionar o Poder Judiciário, atinge a pretensão buscada na inicial, qual seja: a garantia do seu direito à saúde, à educação, ao transporte.

Não há, na prática jurisprudencial brasileira, ainda que em tempos de judicialização dos direitos sociais - especialmente do direito à saúde -, a intervenção em políticas públicas ou a determinação de sua execução. Há o discurso do Supremo Tribunal Federal, mas não há a sua efetiva intervenção.

\title{
THE BRAZILIAN FEDERAL SUPREME COURT AND THE DISCOURSE OF PUBLIC POLITICS IMPLEMENTATION IN BRAZILIAN JURISPRUDENCE: A PROCEEDING JUSTIFIED IN A OMISSION
}

\begin{abstract}
The value of the formulation of public politics that come to assure fundamental social rights, specially health rights - which wean analyze here - is undeniable. In the matter of health rights, we are able to notice that one of the main forms to materialize these rights are in the accomplishment and formulation of such politics, giving its public character, aiming the assurance for our citizen soft heir rights provided by our Federal Constitution. However, the number of judicial demands looking for the realization of this right is growing, which, although finds its support in the social rights list of article 6 of the Brazilian Constitution, does not have yet its full verification. With this matter in mind, this article seeks analyze, basing itself on the jurisprudence of the highest Brazilian Court, how is happening the intervention, by the Brazilian Supreme Court, in the public politics matter. The governmental omission or inertias the intervention background, being something as an excuse in order for the Judiciary Power to demand to the Public Power an intervention on behalf of the constitutional provisions protection. Therefore, it is intended to analyse, how is treated the intervention exposed and how to apply the Principle to the Separation of Powers in the intervention al relation that's been established. Along these lines, is sought to comprehend how it happens - and if it happens - the determination of public politics criation and execution by the Judicial Power in our country.
\end{abstract}

Key-words: Social Rigths; Constitutional Jurisdiction; omission; Public Politics; Brasilian Supreme Court.

\section{Referências}

ADVOCACIA GERAL DA UNIÃO. Intervenção Judicial na saúde pública: panorama no âmbito da Justiça Federal e Apontamentos na seara das Justiças Estaduais. Disponível em: $<$ http://u.saude.gov.br/images/pdf/2014/maio/29/Panorama-da-judicializa----o---2012--modificado-em-junho-de-2013.pdf $>$. Acesso em: 10 maio 2016.

BITENCOURT. Caroline Müller. Controle Jurisdicional de Políticas Públicas. Porto Alegre: Nuria Fabris Editora, 2013.

BOBBIO, Norberto. A era dos DIREITOS. Nova ed. Rio de Janeiro: Elsevier, 2004. 
BRASIL. Constituição (1988). Constituição da República Federativa do Brasil. Brasília, DF: Senado Federal, 1988.

Lei Complementar n. ${ }^{\circ} 141$, de 13 de janeiro de 2012. Diário Oficial [da] República Federativa do Brasil, Brasília, DF, 16 jan. 2012; Disponível em:

<http://www.planalto.gov.br/ccivil_03/leis/LCP/Lcp141.htm>. Acesso em: 25 maio 2016.

Lei n. ${ }^{\circ}$ 8.069, de 13 de julho de 1990. Estatuto da Criança e do Adolescente. Diário Oficial [da] República Federativa do Brasil, Brasília, DF, 29 set. 1990; Disponível em: < http://www.planalto.gov.br/ccivil_03/leis/L8069.htm>. Acesso em: 25 maio 2016.

Supremo Tribunal Federal. Agravo na Suspensão de Tutela Antecipada $n^{\circ}$ 175, Rel. Ministro Gilmar Ferreira Mendes. DJ, 30/04/2010. Disponível em <http://www.stf.jus.br >. Acesso em: 10 maio 2016.

Supremo Tribunal Federal. Agravo Regimental no Recurso Extraordinário no 603.575, Rel. Ministro Eros Grau. DJ, 14/05/2010. Disponível em <http://www.stf.jus.br >. Acesso em: 10 maio 2016.

. Supremo Tribunal Federal. Arguição de Descumprimento de Preceito Fundamental 45, Rel. Ministro Celso de Mello, julgada em 29/04/04, DJ, 04/05/2004. Disponível em <http://www.stf.jus.br>. Acesso em: 10 maio 2016.

BUCCI, Maria Paula Dallari. O conceito de política pública em direito. In: BUCCI, M. P. D. (Org.). Políticas Públicas: reflexões sobre o conceito jurídico. São Paulo: Saraiva, 2006.

CARA, Juan Carlos Gavara de. La dimensión objetiva de los derechos sociales. In: Cuadernos de derecho Constitucional. Barcelona: Librería Bosch, S.L., 2010.

HACHEM, Daniel Wunder. Derechos fundamentales económicos y sociales y la responsabilidad del Estado por omisión. Estudios Constitucionales, Ano 12, nº 1, 2014.

LEAL, Mônia Clarissa Hennig. A dignidade humana como critério para o controle jurisdicional de políticas públicas: análise crítica da atuação do Supremo Tribunal Federal. In: LEAL, M. C. H.; COSTA, M. M. M. (Org.). Direitos sociais e políticas públicas: desafios contemporâneos. Tomo 14. Santa Cruz do Sul: Edunisc, 2014.

A dignidade humana como critério para o controle jurisdicional de políticas públicas: análise crítica da atuação do Supremo Tribunal Federal brasileiro. 2013.

MAUS, Ingeborg. Judiciário como superego da sociedade: o papel da atividade jurisprudencial na "sociedade órfã". Tradução de: Martonio Lima e Paulo Albuquerque. Novos Estudos - CEBRAP, São Paulo, n. 58, p. 193-202, nov. 2000.

MENDES, Gilmar Ferreira. Direitos Fundamentais e Controle de Constitucionalidade: Estudos de direito constitucional (Série EDB). $4^{\mathrm{a}}$ ed. São Paulo: Editora Saraiva, 2012. 
QUEIROZ, Cristina. O princípio não reversibilidade dos direitos fundamentais sociais: princípios dogmáticos e prática jurisprudencial. Lisboa: Coimbra Editora, 2006.

RODRIGUES, Marta M. Assumpção. Políticas Públicas. In: Folha Explica. São Paulo: Publifolha, 2010.

SARLET, Ingo Wolfgang. A eficácia dos direitos fundamentais. 3. ed. Porto Alegre: Livraria do Advogado, 2003.

TAVARES, A. R.; BUCK, P. Direitos Fundamentais e democracia: complementariedade/contrariedade. In: CLÈVE, C. M.; SARLET, I. W.; PAGLIARINI, A. C. (Org.). Direitos Humanos e Democracia. Rio de Janeiro: Editora Forense, 2007. p. 169186.

\section{Sobre as autoras:}

Mônia Clarissa Henng Leal possui Pós-Doutorado na Ruprecht-Karls Universität Heidelberg (Alemanha) e Doutorado em Direito pela Universidade do Vale do Rio dos Sinos - Unisinos (com pesquisas realizadas junto à Ruprecht-Karls Universität Heidelberg, na Alemanha). Professora do Programa de Pós-Graduação em Direito - Mestrado e Doutorado da Universidade de Santa Cruz do Sul - UNISC, onde ministra as disciplinas de Jurisdição Constitucional e de Controle Jurisdicional de Políticas Públicas, respectivamente. Coordenadora do Grupo de Pesquisa "Jurisdição Constitucional aberta", vinculado ao CNPq. Bolsista de produtividade em pesquisa do CNPq. E-mail: moniah@unisc.br

Maria Valentina de Moraes é Mestranda no Programa de Pós-Graduação Stricto Sensu em Direitos Sociais e Políticas Públicas da Universidade de Santa Cruz do Sul - UNISC, na linha de pesquisa Constitucionalismo Contemporâneo. Bolsista PROSUP/CAPES. Graduada em Direito pela Universidade de Santa Cruz do Sul - UNISC. Membro do Grupo de Pesquisa "Jurisdição Constitucional aberta: uma proposta de discussão da legitimidade e dos limites da jurisdição constitucional - instrumentos teóricos e práticos", vinculado ao CNPq e coordenado pela professora Pós-Drª̂nia Clarissa Hennig Leal. E-mail: mariavalentina.23@ hotmail.com 